\title{
Crescimento e nutrição mineral de cebolinha verde cultivada hidroponicamente sob diferentes concentrações de N, P e K ${ }^{1}$
}

\author{
Josinaldo Lopes Araujo2*, Valdemar Faquin ${ }^{3}$, Danielle Pereira Baliza, \\ Fabrício William de Ávila ${ }^{3}$ Amaralina Celoto Guerrero ${ }^{5}$
}

10.1590/0034-737X201663020015

\section{RESUMO}

Em cultivos hidropônicos de hortaliças folhosas destacam-se, dentre os fatores que influenciam a produção e qualidade do produto, as exigências nutricionais da cultura. Objetivou-se, com este trabalho, avaliar o efeito de concentrações de N, P e K sobre a produção de matéria seca e a nutrição mineral em cebolinha 'Todo ano' (Allium fistulosum L.), cultivada em condições hidropônicas. Foram conduzidos três experimentos, um com cada nutriente em três níveis: deficiente, adequado e excessivo. Empregou-se o delineamento inteiramente casualizado, em esquema de parcelas subdivididas no tempo, com quatro repetições e dez plantas por parcela. Aos 15, 30, 45 e 60 dias após o transplante (DAT), foi avaliada a produção de matéria seca da parte aérea e de raízes. Aos 45 e 60 DAT, avaliaram-se os teores e os acúmulos totais de N, P e K e os teores de Ca e Mg da parte aérea da planta. Em cultivos hidropônicos, as deficiências de N e P são mais limitantes que a de K ao crescimento da cebolinha cultivar 'Todo Ano', sendo que níveis baixos de $\mathrm{P}$ afetam principalmente o crescimento do sistema radicular da planta. A deficiência de $\mathrm{N}$ afeta a absorção de $\mathrm{P}, \mathrm{K}, \mathrm{Ca}$ e $\mathrm{Mg}$. $\mathrm{O}$ excesso de $\mathrm{N}$ em cebolinha manifesta-se pelo crescimento excessivo da parte aérea e pelo aumento da flacidez das folhas. Os excessos de $\mathrm{P}$ e de $\mathrm{K}$ na solução nutritiva não provocam sintomas visuais de toxicidade de $\mathrm{P}$ ou de $\mathrm{K}$, mas níveis excessivos de $\mathrm{K}$ diminuem os teores de $\mathrm{Ca}$ e de $\mathrm{Mg}$ da parte aérea da planta.

Palavras-chave: Allium fistulosum L., cultivo hidropônico, toxicidade, deficiência nutricional, diagnose nutricional.

\section{ABSTRACT \\ Growth and mineral nutrition of green onions grown hydroponically under different $\mathbf{N}, P$ and $K$ concentrations}

In hydroponic cultivation of leafy vegetables, the plant nutritional requirements are among the most important factors that influence production and product quality. The objective of this study was to evaluate the effect of levels of $\mathrm{N}, \mathrm{P}$ and $\mathrm{K}$ on the dry matter production and mineral nutrition of hydroponically grown green onion cultivar "Todo Ano" (Allium fistulosum L.). Experiments were conducted with each nutrient at three levels: starvation, adequate and excessive. The experiments were arranged in a completely randomized design, split plot in time, with four replications and ten plants per plot. At 15, 30, 45 and 60 days after transplanting (DAT), dry matter production of shoots and roots were evaluated. At 45 and 60 DAT, the contents and total accumulation of $\mathrm{N}, \mathrm{P}$ and $\mathrm{K}$ and the contents of $\mathrm{Ca}$ and $\mathrm{Mg}$ in the shoots were evaluated. In hydroponics, $\mathrm{N}$ and $\mathrm{P}$ deficiencies are more limiting than $\mathrm{K}$ deficiency. The growth of green onion cultivar 'Todo Ano ' with low levels of P mainly affected the growth of the root system. Nitrogen deficiency negatively affected

\footnotetext{
Submetido em 25/02/2015 e aprovado em 09/10/2015.

${ }^{1}$ Trabalho desenvolvido na Universidade Federal de Lavras.

ZUniversidade Federal de Campina Grande, Centro de Ciências e Tecnologia Agroalimentar, Pombal, Paraíba, Brasil. jhosinal_araujo@yahoo.com.br

${ }^{3}$ Universidade Federal de Lavras, Departamento de Ciência do Solo, Lavras, Minas Gerais, Brasil. vafquin@dcs.ufla.br

${ }^{4}$ Instituto Federal de Educação, Departamento de Ciência e Tecnologia do Sudeste de Minas Gerais, Bom Sucesso, Minas Gerais, Brasil. danielle.baliza@ifsudestemg.edu.br

${ }^{5}$ Universidade Federal de Campina Grande, Centro de Ciências e Tecnologia Agroalimentar, Pombal, Paraíba, Brasil. maracguerrero@hotmail.com

Autor correspondente: jhosinal_araujo@yahoo.com.br
} 
the absorption of $\mathrm{P}, \mathrm{K}, \mathrm{Ca}$ and $\mathrm{Mg}$. The toxicity of $\mathrm{N}$ in green onion is manifested by excessive growth of the aerial part and increased laxity of the leaves. Excessive $\mathrm{P}$ and $\mathrm{K}$ in the nutrient solution caused no visual symptoms of toxicity of $\mathrm{P}$ or $\mathrm{K}$, but excessive levels of $\mathrm{K}$ decreases the $\mathrm{Ca}$ and $\mathrm{Mg}$ contents in the shoots.

Key words: Allium fistulosum L., hydroponics, toxicity, nutritional deficiency, nutritional diagnosis.

\section{INTRODUÇÃO}

A cebolinha (Allium fistulosum L.) é uma das hortaliças condimentares mais apreciadas na alimentação humana (Cardoso \& Berni, 2012). O cultivar mais tradicional é o 'Todo Ano', que apresenta folhas de coloração verde-clara (Filgueira, 2008). A cebolinha ainda é cultivada de forma tradicional, isto é, em canteiros a céu aberto (Cardoso \& Berni, 2012). Nesse sistema, as plantas ficam expostas a diversos fatores bióticos e abióticos, que podem causar reduções da quantidade e da qualidade do produto colhido.

No Brasil, os cultivos hidropônicos têm-se expandido muito nos últimos anos, principalmente no cultivo de hortaliças, como alface, rúcula, agrião, tomate e outras. Dentre as vantagens deste sistema, destacam-se a possibilidade de cultivo em qualquer época do ano, a uniformização da produção e a diminuição do uso de defensivos agrícolas, pois o cultivo controlado reduz a incidência de pragas e doenças (Furlani et al., 1999; Corrêa et al., 2012).

Os nutrientes nitrogênio $(\mathrm{N})$, fósforo $(\mathrm{P})$ e potássio $(\mathrm{K})$ destacam-se por serem os mais aplicados na agricultura mundial (Marschner, 2012), entretanto, em hidroponia, as quantidades aplicadas de N, P e K são reduzidas, principalmente de $\mathrm{P}$, pois, nessas condições, esse nutriente está livre de reações de adsorção e de precipitação como ocorre no solo (Novais \& Alvarez, 2007). Por causa de suas múltiplas funções nas plantas (Epstein \& Bloom, 2006), mesmo em condições de solução nutritiva, N e K, geralmente, são os nutrientes mais extraídos pelas hortaliças (Filgueiras et al., 2002; Pôrto et al., 2007; Alves et al., 2008; Luz et al., 2009). Dessa forma, sob deficiência desses nutrientes, em hortaliças têm sido relatados diminuição do crescimento da parte aérea (para N) e drástica diminuição do sistema radicular (para P) (Belfort et al., 1983; Bernal et al., 2008; Daflon et al., 2014).

Os macronutrientes N, P e K são conhecidos por dificilmente provocarem sintomas perceptíveis de toxidez às plantas, quando aplicados em níveis excessivos (Epstein \& Bloom, 2006); contudo, na maioria dos casos, sua toxidez manifesta-se pelas interações negativas com outros nutrientes, como a inibição da absorção de cálcio e magnésio pelos excessos de potássio e de nitrogênio na forma de amônio (Kano et al., 2011; Araújo et al., 2012.).
De qualquer forma, o excesso de nutrientes pode ser mais prejudicial às culturas sob condições hidropônicas do que em condições de solo, tendo em vista a maior capacidade de tamponamento, assim como as perdas por diversos fatores, deste último (Novais \& Alvarez, 2007). Alguns trabalhos realizados com cebolinha em sistema hidropônico trataram dos efeitos do nitrogênio e do enxofre sobre o crescimento da cultura (Santos et al., 2005; Liu et al., 2009; Liu et al., 2011). Entretanto, informações sobre os efeitos de N, P e K, no crescimento de hortaliças como a cebolinha, cultivadas hidroponicamente, a exemplo do realizado por Santos et al. (2005), são escassos.

Neste trabalho, objetivou-se avaliar o efeito de concentrações de $\mathrm{N}$, de $\mathrm{P}$ e de $\mathrm{K}$ sobre a produção de matéria seca e a nutrição mineral em cebolinha 'Todo ano' (Allium fistulosum L.), cultivada em condições hidropônicas.

\section{MATERIAL E MÉTODOS}

Três experimentos foram conduzidos, simultaneamente, em casa de vegetação do Departamento de Ciência do Solo da Universidade Federal de Lavras com plantas de cebolinha, cultivar 'Todo ano' (Allium fistulosum L.).

As plântulas de cebolinha foram obtidas da germinação de sementes em bandejas de 128 células, preenchidas com vermiculita média. Cinco dias após a germinação, as plântulas foram transferidas para bandejas de polietileno com 16 L de solução de Hoagland \& Arnon (1950), com $20 \%$ de sua força iônica, para adaptação sem os tratamentos, recebendo arejamento constante. Quando a condutividade elétrica da solução de adaptação atingiu cerca de $30 \%$ da inicial, a solução nutritiva teve sua concentração aumentada para $75 \%$ de sua concentração total, com os respectivos tratamentos. Ressalta-se que a combinação dos sais utilizados na composição da solução de cultivo manteve o equilíbrio entre os tratamentos, compondo-se dos seguintes nutrientes e concentrações: $\mathrm{Ca}=3,75 \mathrm{mmolL}^{-1} ; \mathrm{Mg}=1,5 \mathrm{mmolL}^{-1} ; \mathrm{Cu}=0,3 \mu \mathrm{molL}^{-1} ; \mathrm{B}$ $=46,3 \mu \mathrm{molL}^{-1} ; \mathrm{Fe}=89,6 \mu \mathrm{molL}^{-1} ; \mathrm{Mn}=9,1 \mu \mathrm{molL}^{-1} ; \mathrm{Mo}=$ $0,1 \mu \mathrm{molL}^{-1} \mathrm{e} \mathrm{Zn}=0,76 \mu \mathrm{molL}^{-1}$. Por dificuldades técnicas em relação às fontes dos nutrientes, não foi possível manter constantes as concentrações de enxofre e de cloro entre os tratamentos. Assim, as concentrações desses nutrientes na solução nutritiva, variaram de 1,5 a 3,38 
mmolL ${ }^{-1}$, para o enxofre, e de 0,23 a 11,25 $\mathrm{mmolL}^{-1}$, para o cloro. O volume de solução dos vasos foi completado diariamente com água deionizada e sua substituição foi realizada a cada sete dias, sendo o $\mathrm{pH}$ mantido entre 5,5 e 6,0 pela adição de hidróxido de sódio $(\mathrm{NaOH})$ ou de ácido clorídrico $(\mathrm{HCl}) 1,0 \mathrm{~mol} \mathrm{~L}^{-1}$.

Para os três experimentos, foi utilizado o delineamento experimental inteiramente casualizado, com três concentrações de cada nutriente (deficiente, adequado e tóxico) e quatro parcelas experimentais, sendo cada parcela composta por uma bandeja de $16 \mathrm{~L}$ de solução com 40 plantas, totalizando 36 bandejas e 1.440 plantas, na soma dos três ensaios. Consideraram-se como níveis adequados as concentrações dos nutrientes da solução base de Hoagland e Arnon (1950). Os níveis deficientes (2,25 mmol $\mathrm{L}^{-1} \mathrm{~N} ; 0,22 \mathrm{mmol} \mathrm{L}{ }^{-1} \mathrm{P}$ e $\left.0,75 \mathrm{mmol} \mathrm{L}^{-1} \mathrm{~K}\right)$ e tóxicos $(22,5$ mmol L-1 $\mathrm{N} ; 3,75 \mathrm{mmol} \mathrm{L}^{-1} \mathrm{P}$ e $18,75 \mathrm{mmol} \mathrm{L}^{-1} \mathrm{~K}$ ) foram estabelecidos de forma arbitrária, por falta de informação na literatura.

Nos três experimentos, utilizou-se o esquema de parcelas subdivididas no tempo. Para as variáveis MSPA e MSR, as parcelas foram constituídas pelas três concentrações de cada nutriente (Tabela 1) e, as subparcelas, por quatro períodos de avaliação: 15, 30, 45 e 60 dias após o transplantio (DAT). Para as variáveis teores e acúmulos de $\mathrm{N}$, de $\mathrm{P}$ e de $\mathrm{K}$, as parcelas foram constituídas pelas três concentrações de cada nutriente e as subparcelas por dois períodos de avaliação (45 e 60 DAT).

Aos 15, 30, 45 e 60 DAT, dez das 40 plantas de cada parcela e em cada tratamento foram coletadas, separadas em raiz e parte aérea e secadas em estufa $\left(60^{\circ} \mathrm{C}-65^{\circ} \mathrm{C}\right)$, para a obtenção da matéria seca da parte aérea (MSPA) e da matéria seca de raízes (MSR). Posteriormente, o material, coletado nos períodos de 45 e 60 DAT, foi moído separadamente, para a determinação dos teores e acúmulos de $\mathrm{N}$, de $\mathrm{P}$ e de $\mathrm{K}$ em seus tecidos e dos teores de $\mathrm{Ca}$ e $\mathrm{Mg}$ na parte aérea, conforme Malavolta et al. (1997).

As variáveis MSPA e MSR foram avaliadas mediante análise de variância e ajuste de função exponencial, a 5\% de significância. Para as demais variáveis, realizou-se teste de Tukey, usando-se o programa SAEG, versão 9.0 (SAEG, 2007), a 5\% de probabilidade.

\section{RESULTADOS E DISCUSSÃO}

A produção de matéria seca da parte aérea e das raízes, para as três concentrações dos nutrientes estudadas, ajustou-se ao modelo exponencial, em função dos períodos de avaliação, com crescimento reduzido até os 30 DAT (Figura 1). No experimento com níveis de N, observou-se que a concentração de $2,25 \mathrm{mmoL}^{-1}\left(\mathrm{~N}_{1}\right)$ foi limitante para a produção de matéria seca da parte aérea (Figura 1A). Belfort et al. (1983) observaram, em cebolinha (Allium schoenoprasum L.), que a omissão de $\mathrm{N}$ na solução nutritiva foi o tratamento mais limitante à produção de matéria seca dessa espécie. É indiscutível o papel do $\mathrm{N}$ na produção vegetal, pois o nutriente atua principalmente na formação de compostos orgânicos, como aminoácidos, proteínas, bases nitrogenadas e diversos outros compostos orgânicos (Epstein \& Bloom, 2006). Contudo, o aumento de dez vezes da concentração desse nutriente, tratamento $\left(\mathrm{N}_{3}\right)$, resultou apenas em leve aumento da

Tabela 1: Volumes, em mL, das soluções-estoques, necessários para a obtenção de um litro de cada solução nutritiva correspondente aos tratamentos com N, P e K, considerando-se 75\% da força iônica da solução original, criada por Hoagland e Arnon (1950).

\begin{tabular}{|c|c|c|c|c|c|c|c|c|c|c|}
\hline \multirow{3}{*}{ Solução-estoque } & \multirow{3}{*}{$\begin{array}{c}\text { Concentração } \\
\text { molL }^{-1}\end{array}$} & \multicolumn{9}{|c|}{ Tratamentos e volumes pipetados das soluções-estoques } \\
\hline & & N1 & N2 & N3 & P1 & $\mathbf{P 2}$ & P3 & K1 & K2 & K3 \\
\hline & & \multicolumn{9}{|c|}{$\mathrm{ml} \mathrm{L}^{-1}$} \\
\hline $\mathrm{CaCl}_{2}$ & 1 & 3,75 & 0,00 & 0,00 & 0,00 & 0,00 & 0,00 & 0,00 & 0,00 & 3,75 \\
\hline $\mathrm{KH}_{2} \mathrm{PO}_{4}$ & 1 & 0,75 & 0,75 & 0,75 & 0,23 & 0,75 & 3,75 & 0,75 & 0,75 & 0,75 \\
\hline $\mathrm{K}_{2} \mathrm{SO}_{4}$ & 0,5 & 3,75 & 0,00 & 0,00 & 0,53 & 0,00 & 0,00 & 0,00 & 0,00 & 3,00 \\
\hline $\mathrm{MgSO}_{4}$ & 1 & 1,50 & 1,50 & 1,50 & 1,24 & 1,50 & 1,50 & 1,50 & 1,50 & 1,50 \\
\hline $\mathrm{Ca}\left(\mathrm{NO}_{3}\right)_{2} 4 \mathrm{H}_{2} \mathrm{O}$ & 1 & 0,00 & 3,75 & 3,75 & 3,75 & 3,75 & 3,75 & 3,75 & 3,75 & 0,00 \\
\hline $\mathrm{KNO}_{3}$ & 1 & 0,00 & 3,75 & 3,75 & 3,53 & 3,75 & 0,75 & 0,00 & 3,75 & 11,25 \\
\hline $\mathrm{Mg}\left(\mathrm{NO}_{3}\right)_{2} 6 \mathrm{H}_{2} \mathrm{O}$ & 1 & 0,00 & 0,00 & 0,00 & 0,26 & 0,00 & 0,00 & 0,00 & 0,00 & 0,00 \\
\hline $\mathrm{NH}_{4} \mathrm{NO}_{3}$ & 1 & 1,13 & 0,00 & 5,63 & 0,00 & 0,00 & 1,50 & 1,88 & 0,00 & 0,00 \\
\hline $\mathrm{KCl}$ & 1 & 0,00 & 0,00 & 0,00 & 0,23 & 0,00 & 0,00 & 0,00 & 0,00 & 3,75 \\
\hline $\mathrm{MICRO}^{1}$ & 0 & 1,00 & 1,00 & 1,00 & 1,00 & 1,00 & 1,00 & 1,00 & 1,00 & 1,00 \\
\hline $\mathrm{Fe} \mathrm{EDTA}^{2}$ & 0 & 1,00 & 1,00 & 1,00 & 1,00 & 1,00 & 1,00 & 1,00 & 1,00 & 1,00 \\
\hline
\end{tabular}

$\mathrm{N}_{1}=2,25 \mathrm{mmol} \mathrm{L}{ }^{-1} \mathrm{~N} ; \mathrm{N}_{2}=11,25 \mathrm{mmol} \mathrm{L}^{-1} \mathrm{~N} ; \mathrm{N}_{3}=22,5 \mathrm{mmol} \mathrm{L}^{-1} \mathrm{~N} ; \mathrm{P}_{1}=0,22 \mathrm{mmol} \mathrm{L} \mathrm{P}^{-1} \mathrm{P}_{2}=0,75 \mathrm{mmol} \mathrm{L}^{-1} \mathrm{P} ; \mathrm{P}_{3}=3,75 \mathrm{mmol} \mathrm{L}^{-1}$ $\mathrm{P} ; \mathrm{K}_{1}=0,75 \mathrm{mmol} \mathrm{L}-1 \mathrm{~K} ; \mathrm{K}_{2}=4,5 \mathrm{mmol} \mathrm{L}^{-1} \mathrm{~K} ; \mathrm{K}_{3}^{3}=18,75 \mathrm{mmol} \mathrm{L}^{-1} \mathrm{~K}$.

${ }^{1}$ Dissolveram-se em $1 \mathrm{~L}$ de água: $1,81 \mathrm{~g} \mathrm{MnCl}_{2} .4 \mathrm{H}_{2} \mathrm{O} ; 0,08 \mathrm{~g} \mathrm{CuSO}_{4} .5 \mathrm{H}_{2} \mathrm{O} ; 0,02 \mathrm{~g} \mathrm{H}_{2} \mathrm{MoO}_{4} .2 \mathrm{H}_{2} \mathrm{O} ; 2,86 \mathrm{~g} \mathrm{H}_{3} \mathrm{BO}_{3} ; 0,22 \mathrm{~g} \mathrm{ZnSO} .7 \mathrm{H}_{2} \mathrm{O}$.

${ }^{2}$ Dissolveu-se: (a) $33,3 \mathrm{~g} \mathrm{Na}_{2}$-EDTA em cerca de $500 \mathrm{~mL}$ de água morna $\left( \pm 30{ }^{\circ} \mathrm{C}\right)$ contendo $100,4 \mathrm{~mL} \mathrm{de} \mathrm{NaOH} 1 \mathrm{molL}{ }^{-1}$; (b) $24,9 \mathrm{~g}$ $\mathrm{FeSO}_{4} \cdot 7 \mathrm{H}_{2} \mathrm{O}$ em cerca de $300 \mathrm{~mL}$ de água quente $\left( \pm 70{ }^{\circ} \mathrm{C}\right)$, contendo $4 \mathrm{~mL}$ de $\mathrm{HCl} 1,0 \mathrm{molL}^{-1}$; (c) Misturou-se a e b adicionando-se água até $\pm 950 \mathrm{~mL}$; colocou-se aeração constante por $12 \mathrm{~h}$ e completou-se o volume para $1 \mathrm{~L}$. 
matéria seca da parte aérea, quando comparado com o nível considerado adequado $\left(\mathrm{N}_{2}\right)$. Aos 60 DAT, observou-se que, nas plantas cultivadas com a concentração mais elevada de $\mathrm{N}$, as folhas apresentavam-se flácidas e com tombamento sobre as bandejas, pois a elevada concentração promoveu crescimento vegetativo excessivo, fato não observado nos demais tratamentos. Este efeito provavelmente se deve ao aumento da concentração de proteínas nas folhas, em detrimento da síntese de compostos ricos em lignina, bem como à diminuição da espessura e da lignificação da parede celular (Marschner, 2012). Nas raízes (Figura 1B), embora com o tratamento
$\mathrm{N}_{3}$ a produção de matéria seca tenha sido superior, praticamente não houve diferença entre o tratamento adequado e o deficiente. Este efeito possivelmente foi proporcionado pela resposta da planta à carência de $\mathrm{N}$ no nível deficiente, pois, normalmente, plantas deficientes em nutrientes elevam a translocação de fotoassimilados para as raízes, resultando em aumento do sistema radicular em detrimento da parte aérea, independentemente do meio de cultivo (Araújo et al., 2012).

Os teores de $\mathrm{N}$ e de $\mathrm{P}$, em todas as concentrações de $\mathrm{N}$ no meio de cultivo, praticamente não foram alterados entre os períodos de 45 DAT e 60 DAT, com exceção para o
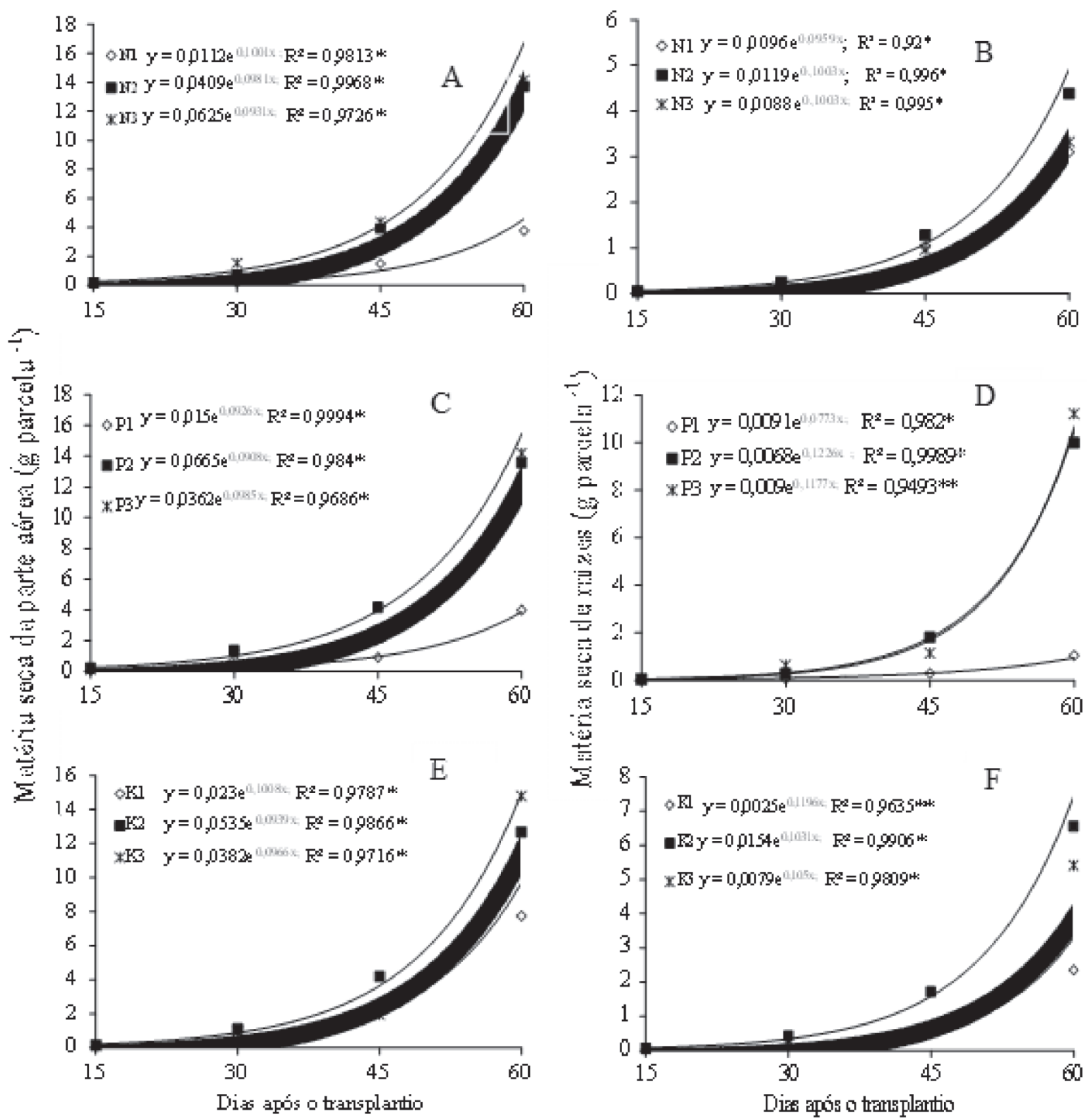

Figura 1: Produção de matéria seca da parte aérea e das raízes de cebolinha, cv 'Todo Ano', em função dos dias após o transplantio e dos níveis de nitrogênio (A e B), de fósforo (C e D) e de potássio (E e F) na solução nutritiva. $\mathrm{N}_{1}=2,25 \mathrm{mmol} \mathrm{L}^{-1} \mathrm{~N} ; \mathrm{N}_{2}=11,25 \mathrm{mmol}$ $\mathrm{L}^{-1} \mathrm{~N} ; \mathrm{N}_{3}=22,5 \mathrm{mmol} \mathrm{L}^{-1} \mathrm{~N} ; \mathrm{P}_{1}=0,22 \mathrm{mmol} \mathrm{L}^{-1} \mathrm{P} ; \mathrm{P}_{2}=0,75 \mathrm{mmol} \mathrm{L}^{-1} \mathrm{P} ; \mathrm{P}_{3}=3,75 \mathrm{mmol} \mathrm{L}^{-1} \mathrm{P} ; \mathrm{K}_{1}=0,75 \mathrm{mmol} \mathrm{L}^{-1} \mathrm{~K} ; \mathrm{K}_{2}=4,5 \mathrm{mmol}$ $\mathrm{L}^{-1} \mathrm{~K} ; \mathrm{K}_{3}=18,75 \mathrm{mmol} \mathrm{L}^{-1} \mathrm{~K}$. 
tratamento $\mathrm{N}_{1}$, que resultou em menor teor de $\mathrm{N}$, aos 60 DAT, da parte aérea (Tabela 2). Os teores de K, por outro lado, diminuíram aos 60 DAT, indicando que em cebolinha este nutriente é, provavelmente, mais móvel que N e P. Os teores de $\mathrm{N}$ diminuíram gradativamente, conforme diminuição da concentração do nutriente na solução nutritiva, nas duas épocas de avaliação.

No tratamento $\mathrm{N}_{1}$, aos 60 DAT, observaram-se sintomas visuais de deficiência de $\mathrm{N}$, que se manifestaram como clorose generalizada, acompanhada de seca do ápice das folhas mais velhas. Sintomas similares a estes foram observados em cebolinha (Allium schoenoprasum), por Belfort et al. (1983) e Bernal et al. (2008), ambos os trabalhos em solução nutritiva.

Apenas aos 60 DAT, os teores de P e K diminuíram no tratamento $\mathrm{N}_{1}$, como uma provável resposta da diminuição do crescimento radicular, diminuindo a absorção desses nutrientes (Marschner, 2012). Nas raízes, os comportamentos para os teores de $\mathrm{N}$, de $\mathrm{P}$ e de $\mathrm{K}$ foram semelhantes aos da parte aérea, ou seja, as épocas não afetaram os teores desses nutrientes.e a concentração de $\mathrm{N}$ aumentou conforme o aumento das concentrações do nutriente no meio de cultivo, enquanto as concentrações de $\mathrm{P}$ e de $\mathrm{K}$ não apresentaram uma tendência definida. Os acúmulos de N, de $\mathrm{P}$ e de K refletiram-se na produção de matéria seca e na concentração desses nutrientes nos tecidos da cebolinha, ou seja, o maior acúmulo desses nutrientes ocorreu aos 60 DAT e os menores valores foram obtidos no tratamento $\mathrm{N}_{1}$ (Tabela 2). Observou-se grande discrepância entre a quantidade de $\mathrm{N}$, acumulada no tratamento $\mathrm{N}_{3}$ e a produção de matéria seca desse tratamento (Figura 1A), fato explicado pelo consumo de luxo (Malavolta et al., 1997).

Assim como ocorreu no experimento com N, o crescimento da parte aérea da cebolinha foi muito limitado no tratamento $\mathrm{P}_{1}$ (Figura 1C). Contudo, diferentemente do ensaio com N, a baixa concentração de $\mathrm{P}$ afetou drasticamente o crescimento radicular da planta (Figura 1D). Neste tratamento, a partir dos 30 DAT, as plantas apresentaram sintomas visuais típicos de deficiência de $\mathrm{P}$, com pequeno crescimento da planta e escurecimento das folhas. Esses sintomas coincidem com a descrição de Daflon et al. (2014), para coentro, e com a descrição de Belfort et al. (1983) e Bernal et al. (2008), para cebolinha.

As causas do pequeno crescimento das plantas com deficiência de $\mathrm{P}$ já são bem conhecidas e devem-se à participação do nutriente em importantes biomoléculas, como DNA, RNA, fosfolipídios de membranas, com participação nos diversos processos metabólicos vitais para as plantas, como a transferência de energia e a ativação e a desativação enzimática (Epstein \& Bloom, 2006). Por outro lado, elevada concentração de $\mathrm{P}$ na solução não resultou em sintomas visuais de toxidez, assim como também não aumentou a produção de matéria seca das plantas.
Em relação aos teores de N, P e K (Tabela 2) da parte aérea da planta e das raízes, para os níveis de $\mathrm{P}$, exceto para teores, aos 60 DAT, da parte aérea e da raiz, observou-se, em ambas as épocas de avaliação, aumento do teor de $\mathrm{N}$ no tratamento $\mathrm{P}_{1}$, o que provavelmente se deve ao efeito de concentração, efeito muito comum para o fósforo (Araújo et al., 2013). Os teores de P, exceto nas raízes, não foram afetados pelos níveis desse nutriente na solução, aos 45 DAT, mas aos 60 DAT observou-se drástica diminuição, provavelmente como resposta da planta, ao crescimento exponencial da parte aérea (Figura $1 \mathrm{C}$ ). As quantidades acumuladas de $\mathrm{N}$, de $\mathrm{P}$ e de $\mathrm{K}$ foram superiores às dos $60 \mathrm{DAT}$, por causa da maior produção de matéria seca nessa época (Figura 1C). Da mesma forma como ocorreu para o $\mathrm{N}$, as quantidades acumuladas desse nutriente aumentaram conforme o aumento das concentrações de $\mathrm{P}$ na solução; entretanto, para os totais acumulados de $\mathrm{P}$ e de $\mathrm{K}$ aos $60 \mathrm{DAT}$, não houve diferença entre as concentrações consideradas adequada e tóxica, de $\mathrm{P}$.

A resposta da cebolinha às concentrações de $\mathrm{K}$ (Figura 1E e 1F) foi mais gradual em comparação com as repostas às concentrações de $\mathrm{N}$ e de $\mathrm{P}$, nos respectivos ensaios (Figura 1A e 1B). Diferentemente do que ocorreu nos ensaios anteriores, observou-se que a redução da concentração de K em seis vezes (nível deficiente) não provocou redução do crescimento das plantas, de forma tão acentuada quanto as reduções das concentrações de $\mathrm{N}$ e de $\mathrm{P}$, na mesma proporção. Esse fato confirma o que geralmente é preconizado na literatura, que os nutrientes $\mathrm{N}$ e $\mathrm{P}$, geralmente, são os mais envolvidos diretamente com o crescimento vegetal (Epstein \& Bloom, 2006; Marschner, 2012). Com cultivares de cebola, Cecílio Filho et al. (2009) observaram, em experimento de campo, que a resposta da cultura a doses de $\mathrm{K}$ foi menos pronunciada que a doses de $\mathrm{N}$. Entretanto, com o menor nível de $\mathrm{K}$, foram observados sintomas visuais típicos de deficiência de $\mathrm{K}$, como seca e necrose do ápice e manchas escuras das folhas mais velhas, semelhantes aos descritos por Belfort et al. (1983), em cebolinha. Esses autores acrescentam que, mesmo com sintomas visuais de deficiência de $\mathrm{K}$, as plantas ainda apresentavam bom porte, como ocorreu neste trabalho. Na maior concentração de $\mathrm{K}$, não se observaram sintomas visuais de toxicidade por excesso de K; ao contrário, esta concentração parece ter estimulado o crescimento das raízes (Figura 1F).

Para os teores de N, de P e de K da parte aérea, observou-se variação entre os períodos apenas para $\mathrm{N}$ e $\mathrm{P}$, no nível de $\mathrm{K}$ considerado deficiente, os quais diminuíram aos 60 DAT (Tabela 1). Nas raízes, houve diminuição dos teores de $\mathrm{P}$ e de $\mathrm{K}$ aos 60 DAT, sendo a de $\mathrm{P}$ em todos os níveis de K na solução e, a de K, no nível deficiente desse nutriente. Na comparação dos níveis de K, observaram-se, 
em ambas as partes da planta, elevações das concentrações de $\mathrm{N}$ e de $\mathrm{P}$ no menor nível de K, provavelmente, por efeito de concentração (Malavolta et al., 2006). O teor de $\mathrm{K}$, por outro lado, diminuiu aos 60 DAT no menor nível desse nutriente, tanto na parte aérea quanto nas raízes, fato decorrente provavelmente do aumento da demanda de K com o crescimento da planta. Assim como ocorreu nos ensaios com $\mathrm{N}$ e $\mathrm{P}$, o acúmulo total de nutrientes, em função da concentração de $\mathrm{K}$ e dos estádios de crescimento foram sempre superiores aos 60 DAT e, em geral, no maior nível de K (Tabela 1). Isso pode ser explicado pela maior produção de matéria seca nos maiores níveis de $\mathrm{K}$

Tabela 2: Teores e acúmulos de nitrogênio (N), fósforo (P) e potássio (K) da matéria seca da parte aérea e das raízes de cebolinha, cv ‘Todo Ano', em função dos dias após o transplantio (DAT) e dos níveis de nitrogênio, de fósforo e de potássio na solução nutritiva.

\begin{tabular}{|c|c|c|c|c|c|c|}
\hline \multirow{2}{*}{ Tratamentos } & \multicolumn{2}{|c|}{ Nitrogênio } & \multicolumn{2}{|c|}{ Fósforo } & \multicolumn{2}{|c|}{ Potássio } \\
\hline & 45 DAT & 60 DAT & 45 DAT & 60 DAT & 45 DAT & 60 DAT \\
\hline \multirow[t]{2}{*}{ Nitrogênio } & \multicolumn{6}{|c|}{ Teores $\left(\mathrm{g} \mathrm{kg}^{-1}\right)$} \\
\hline & \multicolumn{4}{|c|}{ Parte aérea } & & \\
\hline $\mathrm{N}_{1}$ & $28,97 \mathrm{cA}$ & $27,36 \mathrm{cB}$ & $5,50 \mathrm{aA}$ & $3,98 \mathrm{bA}$ & $15,98 \mathrm{aA}$ & $12,13 \mathrm{bB}$ \\
\hline $\mathrm{N}_{2}$ & $40,87 \mathrm{bA}$ & $39,83 \mathrm{bA}$ & $5,29 \mathrm{aA}$ & $5,00 \mathrm{aA}$ & 16,08 a A & $14,67 \mathrm{bB}$ \\
\hline \multirow{2}{*}{$\mathrm{N}_{3}^{2}$} & $58,89 \mathrm{aA}$ & $56,00 \mathrm{aA}$ & $4,97 \mathrm{aA}$ & $4,46 \mathrm{aA}$ & 17,21 a A & 15,94 a B \\
\hline & \multicolumn{6}{|c|}{ Raízes } \\
\hline $\mathrm{N}_{1}$ & $31,62 \mathrm{cA}$ & $18,04 \mathrm{cB}$ & $7,55 \mathrm{aA}$ & $5,74 \mathrm{cB}$ & $19,04 \mathrm{aA}$ & $19,75 \mathrm{aA}$ \\
\hline $\mathrm{N}_{2}$ & $35,08 \mathrm{bA}$ & $34,11 \mathrm{bA}$ & $5,89 \mathrm{bA}$ & $6,48 \mathrm{bA}$ & $12,12 \mathrm{aB}$ & $18,20 \mathrm{aA}$ \\
\hline \multirow[t]{2}{*}{$\mathrm{N}_{3}$} & $58,41 \mathrm{cA}$ & $57,69 \mathrm{aA}$ & $8,75 \mathrm{bA}$ & 7,27 a B & $18,20 \mathrm{aA}$ & $17,49 \mathrm{aA}$ \\
\hline & \multicolumn{6}{|c|}{ Acúmulo total (mg parcela $\left.{ }^{-1}\right)$} \\
\hline $\mathrm{N}_{1}$ & $75,77 \mathrm{cB}$ & $159,28 \mathrm{cA}$ & $15,93 \mathrm{bB}$ & $32,49 \mathrm{cA}$ & $43,44 \mathrm{cB}$ & $106,08 \mathrm{bA}$ \\
\hline $\mathrm{N}_{2}$ & $205,28 \mathrm{bB}$ & $698,74 \mathrm{bA}$ & $28,36 \mathrm{aB}$ & $87,31 \mathrm{bA}$ & $78,79 \mathrm{bB}$ & $280,34 \mathrm{aA}$ \\
\hline $\mathrm{N}_{3}$ & $309,70 \mathrm{aB}$ & $983,44 \mathrm{aA}$ & $30,45 \mathrm{aB}$ & $96,83 \mathrm{aA}$ & $94,61 \mathrm{aB}$ & $283,20 \mathrm{aA}$ \\
\hline \multirow[t]{2}{*}{ Fósforo } & \multicolumn{6}{|c|}{ Teores $\left(\mathrm{g} \mathrm{kg}^{-1}\right)$} \\
\hline & Parte aérea & & & & & \\
\hline $\mathrm{P}_{1}$ & $62,04 \mathrm{aA}$ & 59,14 aA & $4,93 \mathrm{aA}$ & $2,17 \mathrm{bB}$ & $18,65 \mathrm{bA}$ & 24,89 aA \\
\hline $\mathrm{P}_{2}$ & 39,82 bA & $34,28 \mathrm{bA}$ & $5,20 \mathrm{aA}$ & 5,12 aA & 27,58 a $\mathrm{A}$ & 26,36 aA \\
\hline \multirow[t]{2}{*}{$\mathrm{P}_{3}$} & $41,52 \mathrm{bBA}$ & $38,38 \mathrm{bBA}$ & $5,49 \mathrm{aA}$ & $4,63 \mathrm{aB}$ & $21,54 \mathrm{bA}$ & 21,77 aA \\
\hline & \multicolumn{6}{|c|}{ Raízes } \\
\hline $\mathrm{P}_{1}$ & $47,31 \mathrm{aA}$ & $47,32 \mathrm{aA}$ & $23,43 \mathrm{aA}$ & $2,52 \mathrm{bB}$ & $57,36 \mathrm{aA}$ & $18,90 \mathrm{aB}$ \\
\hline $\mathrm{P}_{2}$ & 37,65 bA & $33,31 \mathrm{bA}$ & $6,08 \mathrm{bA}$ & $5,23 \mathrm{abA}$ & $13,54 \mathrm{bA}$ & $17,91 \mathrm{aA}$ \\
\hline $\mathrm{P}_{3}$ & $36,45 \mathrm{bA}$ & 31,86 bA & $10,13 \mathrm{bA}$ & $11,79 \mathrm{aA}$ & $14,67 \mathrm{bA}$ & $17,21 \mathrm{aA}$ \\
\hline $\mathrm{P}_{1}$ & $70,51 \mathrm{cB}$ & $283,65 \mathrm{bA}$ & $10,41 \mathrm{cB}$ & $10,79 \mathrm{cA}$ & $34,05 \mathrm{cB}$ & $119,51 \mathrm{bA}$ \\
\hline $\mathrm{P}_{2}$ & $133,68 \mathrm{bB}$ & $800,08 \mathrm{aA}$ & $23,81 \mathrm{bB}$ & $121,91 \mathrm{bA}$ & $65,73 \mathrm{bB}$ & $501,43 \mathrm{aA}$ \\
\hline $\mathrm{P}_{3}$ & $232,42 \mathrm{aB}$ & $901,97 \mathrm{aA}$ & $32,47 \mathrm{aB}$ & $196,68 \mathrm{aA}$ & $135,28 \mathrm{aB}$ & $535,57 \mathrm{aA}$ \\
\hline \multirow[t]{2}{*}{ Potássio } & \multicolumn{6}{|c|}{ Teores $\left(\mathrm{g} \mathrm{kg}^{-1}\right)$} \\
\hline & \multicolumn{6}{|c|}{ Parte aérea } \\
\hline $\mathrm{K}_{1}$ & $61,07 \mathrm{aA}$ & $57,21 \mathrm{aB}$ & $9,21 \mathrm{aA}$ & $6,92 \mathrm{aB}$ & $18,62 \mathrm{aA}$ & $15,38 \mathrm{bA}$ \\
\hline $\mathrm{K}_{2}$ & $43,44 \mathrm{bA}$ & $39,10 \mathrm{bA}$ & $5,41 \mathrm{bA}$ & $4,26 \mathrm{bA}$ & $14,39 \mathrm{aA}$ & $18,06 \mathrm{aA}$ \\
\hline \multirow[t]{2}{*}{$\mathrm{K}_{3}^{2}$} & $47,07 \mathrm{bA}$ & $44,41 \mathrm{bA}$ & $5,56 \mathrm{bA}$ & $4,91 \mathrm{bA}$ & $19,04 \mathrm{aA}$ & $17,21 \mathrm{aA}$ \\
\hline & \multicolumn{6}{|c|}{ Raízes } \\
\hline $\mathrm{K}_{1}$ & $57,69 \mathrm{aA}$ & $48,52 \mathrm{aA}$ & $12,34 \mathrm{aA}$ & $8,12 \mathrm{aB}$ & 20,17 a A & $11,71 \mathrm{cB}$ \\
\hline $\mathrm{K}_{2}$ & $37,17 \mathrm{bA}$ & $26,79 \mathrm{bA}$ & $5,20 \mathrm{cA}$ & $3,41 \mathrm{bB}$ & $19,32 \mathrm{aA}$ & $14,53 \mathrm{bA}$ \\
\hline $\mathrm{K}_{3}$ & $40,79 \mathrm{bA}$ & $31,62 \mathrm{bA}$ & $7,71 \mathrm{bA}$ & $4,58 \mathrm{bB}$ & $15,52 \mathrm{aA}$ & 17,49 aA \\
\hline $\mathrm{K}_{1}$ & $116,39 \mathrm{cB}$ & $558,91 \mathrm{cA}$ & $15,29 \mathrm{bB}$ & $71,75 \mathrm{bA}$ & $46,29 \mathrm{cB}$ & $145,06 \mathrm{bA}$ \\
\hline $\mathrm{K}_{2}$ & 199,48 bB & $668,8 \mathrm{bA}$ & $31,52 \mathrm{aB}$ & $76,46 \mathrm{bA}$ & $69,93 \mathrm{bB}$ & 327,36 aA \\
\hline $\mathrm{K}_{3}$ & $246,78 \mathrm{aB}$ & $823,00 \mathrm{aA}$ & $32,69 \mathrm{aB}$ & $96,95 \mathrm{aA}$ & $93,39 \mathrm{aB}$ & $349,07 \mathrm{aA}$ \\
\hline
\end{tabular}

Letras minúsculas comparam os níveis dos nutrientes dentro de cada período de avaliação e maiúsculas comparam os períodos de avaliação dentro de cada nível do nutriente, a $5 \%$ de probabilidade. $\mathrm{N}_{1}=2,25 \mathrm{mmol} \mathrm{L}-1 \mathrm{~N} ; \mathrm{N}_{2}=11,25 \mathrm{mmol} \mathrm{L}^{-1} \mathrm{~N} ; \mathrm{N}_{3}=22,5 \mathrm{mmol} \mathrm{L}^{-1} \mathrm{~N} ; \mathrm{P}_{1}=0,22$ mmol L-1 P; $\mathrm{P}_{2}=0,75 \mathrm{mmol} \mathrm{L}^{-1} \mathrm{P} ; \mathrm{P}_{3}=3,75 \mathrm{mmol} \mathrm{L}^{-1} \mathrm{P} ; \mathrm{K}_{1}=0,75 \mathrm{mmol} \mathrm{L}^{-1} \mathrm{~K} ; \mathrm{K}_{2}=4,5 \mathrm{mmol} \mathrm{L}^{-1} \mathrm{~K} ; \mathrm{K}_{3}=18,75 \mathrm{mmol} \mathrm{L}^{-1} \mathrm{~K}$. 
aos 60 DAT, pois os teores de N, de P e de K nem sempre seguiram essa lógica.

Considerando-se os três experimentos, verificou-se que o acúmulo de nutrientes seguiu a ordem $\mathrm{N}>\mathrm{K}>\mathrm{P}$, sequência geralmente observada com a maioria das espécies vegetais (Malavolta et al., 1997), embora em hortaliças folhosas, como a alface, a extração de K seja superior à de N (Filgueiras et al., 2002; Kano et al., 2011). Observou-se, ainda, que, dos três nutrientes testados, a magnitude da resposta aos níveis dos nutrientes foi menor para o $\mathrm{K}$, indicando que a planta é mais responsiva ao $\mathrm{N}$ e ao $\mathrm{P}$.

Em relação aos teores foliares de cálcio e de magnésio (Tabela 3), verificou-se que no ensaio com níveis de N, os teores destes nutrientes, na parte aérea, em ambos os períodos de avaliação, foram menores no tratamento $\mathrm{N}_{1}$ (adequado). Nas raízes, esse efeito foi observado apenas para o $\mathrm{Ca}$. Estes resultados estão coerentes com os observados para os teores de $\mathrm{P}$ e de $\mathrm{K}$ neste traba- lho. Resende et al. (2009) também observaram, em alface americana, diminuição dos teores de $\mathrm{Ca}$ e de $\mathrm{Mg}$ com a diminuição do suprimento de $\mathrm{N}$ à cultura. Esse efeito pode ser consequência da diminuição da absorção radicular desses nutrientes, tendo em vista que a deficiência de $\mathrm{N}$ afeta o metabolismo geral da planta, diminuindo a síntese de proteínas, inclusive a síntese de transportadores de membranas, responsáveis pelo transporte ativo de $\mathrm{Ca}$ e $\mathrm{Mg}$ (Taiz \& Zeiger, 2004). No que se refere às épocas de avaliação, na parte aérea, os teores de Mg diminuíram aos 60 DAT, fato relacionado com sua maior mobilidade no floema e, portanto, com sua maior redistribuição na planta, o que não ocorreu com o cálcio, que é considerado praticamente imóvel no floema (Malavolta et al., 1997),.

No ensaio com concentrações de fósforo, os teores de Ca da parte aérea não foram influenciados pelos níveis de P em solução nutritiva (Tabela 3). Os teores de Mg dessa parte foram superiores no nível $\mathrm{P}_{2}$ aos 45 DAT, e mantive-

Tabela 3: Teores de cálcio e magnésio na matéria seca da parte aérea e raízes de cebolinha, cv ‘Todo Ano’ em função dos dias após o transplantio (DAT) e níveis de nitrogênio, fósforo e potássio da solução nutritiva.

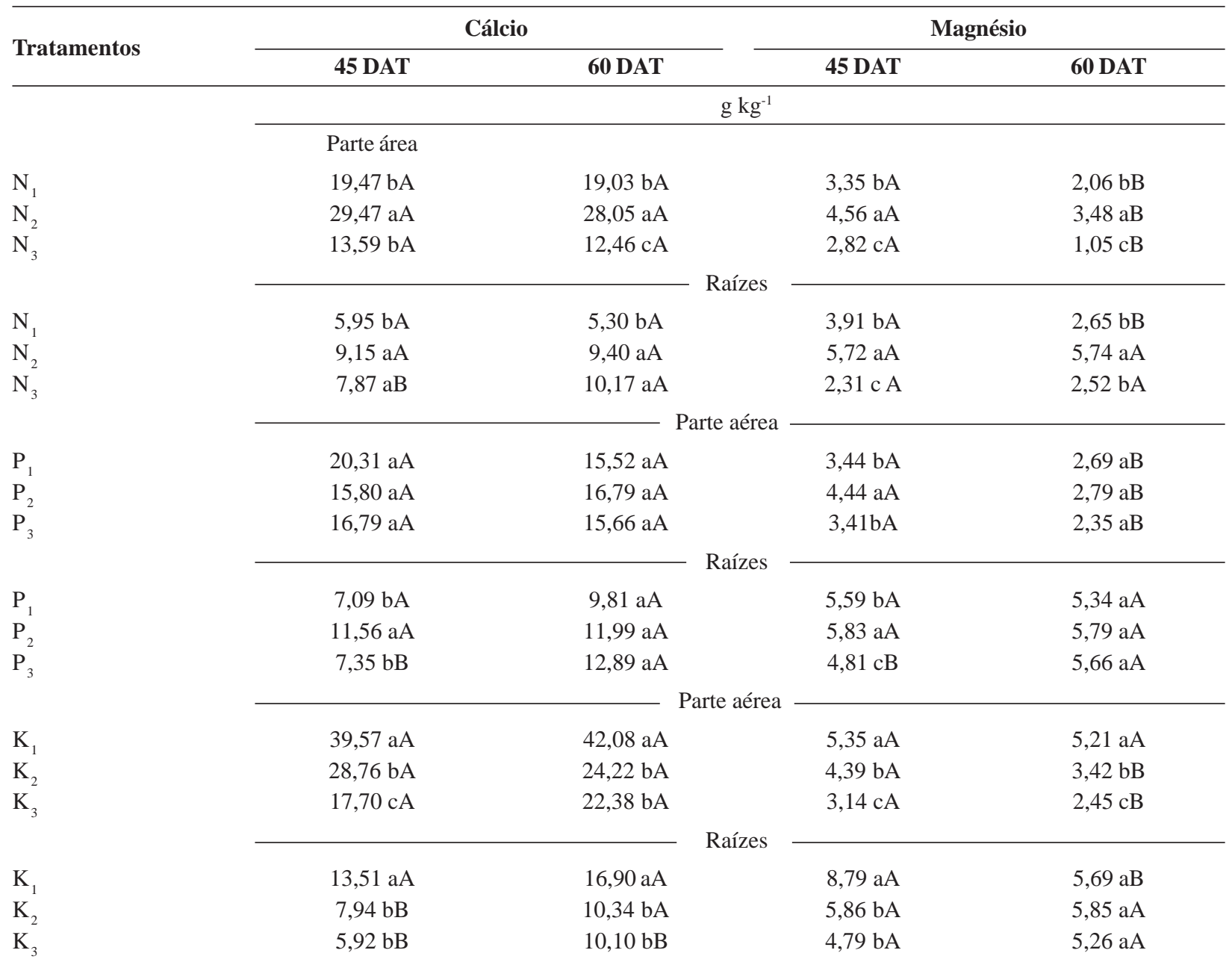

Letras minúsculas comparam os teores dos nutrientes dentro de cada período de avaliação e maiúsculas comparam os períodos de avaliação dentro de cada nível do nutriente, a $5 \%$ de probabilidade. $\mathrm{N}_{1}=2,25 \mathrm{mmol} \mathrm{L}-1 \mathrm{~N} ; \mathrm{N}_{2}=11,25 \mathrm{mmol} \mathrm{L}^{-1} \mathrm{~N}_{2} \mathrm{~N}_{3}=22,5 \mathrm{mmol} \mathrm{L}^{-1} \mathrm{~N} ; \mathrm{P}_{1}=0,22$ $\mathrm{mmol} \mathrm{L}-1 \mathrm{P} ; \mathrm{P}_{2}=0,75 \mathrm{mmol} \mathrm{L}-1 \mathrm{P} ; \mathrm{P}_{3}=3,75 \mathrm{mmol} \mathrm{L}^{-1} \mathrm{P} ; \mathrm{K}_{1}=0,75 \mathrm{mmol} \mathrm{L}-1 \mathrm{~K} ; \mathrm{K}_{2}=4,5 \mathrm{mmol} \mathrm{L}^{-1} \mathrm{~K} ; \mathrm{K}_{3}=18,75 \mathrm{mmol} \mathrm{L} \mathrm{K}^{-1}$ 
ram-se inalterados aos 60 DAT. Considerando-se o papel do P no crescimento radicular e seu reflexo na absorção de nutrientes, esperava-se diminuição da absorção de Ca no menor nível de $\mathrm{P}$, como observado em outros trabalhos (Quadros et al., 2011; Nakagawa \& Rosolem, 2005). Nas raízes, aos $45 \mathrm{DAT}$, os maiores teores de Ca e de $\mathrm{Mg}$ foram obtidos no tratamento $\mathrm{P}_{2}$, enquanto, aos 60 DAT, não houve diferença entre os níveis de $\mathrm{P}$ para as concentrações desses nutrientes. Assim como no ensaio com níveis de N, os teores de $\mathrm{Mg}$ da parte aérea diminuíram aos 60 DAT, mas os de Ca mantiveram-se inalterados entre os períodos de avaliação (Tabela 3).

Diferentemente do que ocorreu nos ensaios com níveis de $\mathrm{N}$ e de $\mathrm{P}$, a elevação da concentração de $\mathrm{K}$ na solução nutritiva proporcionou decréscimos das concentrações de Ca e de $\mathrm{Mg}$ da parte aérea da cebolinha, tanto aos 45 quanto aos 60 DAT. Nas raízes, o efeito foi praticamente o mesmo, com exceção dos teores de Mg aos 60 DAT, quando os níveis de $\mathrm{K}$ não afetaram os teores desse nutriente. A diminuição dos teores de $\mathrm{Ca}$ e $\mathrm{Mg}$ da parte área, por elevação do K na solução nutritiva, devese, provavelmente, à inibição competitiva, durante o processo de absorção iônica dos íons $\mathrm{K}^{+}$em relação aos primeiros, fato já bastante conhecido na literatura (Epstein \& Bloom, 2006). Santos et al. (2005) não observaram diminuição dos teores de $\mathrm{Ca}$ e de $\mathrm{Mg}$ em cebolinha por aumento das concentrações de $\mathrm{K}$, em até $15,0 \mathrm{mmoL}^{-1}$. Por outro lado, Kano et al. (2010), em experimento de campo, observaram decréscimo linear dos teores de $\mathrm{Mg}$ em alface, com o aumento das doses de $\mathrm{K}$, mas os teores de Ca mantiveram-se inalterados.

\section{CONCLUSÕES}

Em cultivo hidropônico, as deficiências de $\mathrm{N}$ e de $\mathrm{P}$ são mais limitantes que as de $\mathrm{K}$ ao crescimento da cebolinha cultivar 'Todo Ano'. Níveis baixos de P afetam principalmente o crescimento do sistema radicular da planta. A deficiência de $\mathrm{N}$ afeta as absorções de $\mathrm{P}$, de $\mathrm{K}$, $\mathrm{Ca}$ e de $\mathrm{Mg}$.

$\mathrm{O}$ excesso de $\mathrm{N}$ em cebolinha manifesta-se pelo crescimento excessivo da parte aérea e pelo aumento da flacidez das folhas. Os excessos de $\mathrm{P}$ e de $\mathrm{K}$ na solução nutritiva não provocam sintomas visuais de toxicidade de $\mathrm{P}$ ou de $\mathrm{K}$, mas níveis excessivos de $\mathrm{K}$, diminuem os teores de Ca e de $\mathrm{Mg}$ da parte aérea da planta.

\section{AGRADECIMENTOS}

Os autores agradecem ao Departamento de Ciência do Solo da Universidade Federal de Lavras e ao Conselho Nacional de Desenvolvimento Científico e Tecnológico (CNPq), pela concessão da Bolsa de Iniciação Científica a um dos autores do trabalho.

\section{REFERÊNCIAS}

Alves AU, Prado RM, Gondim ARO, Fonseca IM \& Cecílio Filho AB (2008) Desenvolvimento e estado nutricional da beterraba em função da omissão de nutrientes. Horticultura Brasileira, 26:292-295.

Araújo JL, Faquin V, Ávila FW \& Pedroso TQ (2013) Interação fosfito e fosfato no crescimento e na nutrição fosfatada do feijoeiro em solução nutritiva. Revista Brasileira de Ciência do Solo, 37:482-490.

Araújo JL, Faquin V, Vieira NMB, Oliveira MVC, Soares AA, Rodrigues CR \& Mesquita AC (2012) Crescimento e produção do arroz sob diferentes proporções de nitrato e amônio. Revista Brasileira de Ciência do Solo, 36:921-930.

Belfort CC \& Haag HP (1983) Nutrição mineral de hortaliças: LVI - Carência de macronutrientes em cebolinha (Allium schoenoprasum). Anais da Escola Superior de Agricultura Luiz de Queiroz, 90:231-234.

Bernal DA, Morales LC, Fischer G, Cuevo J \& Magnitskiy S (2008) Caracterización de las deficiencias de macronutrientes en plantas de cebollín (Allium schoenoprasum L.). Revista Colombiana de Ciências Hortícolas, 2:192-204.

Cardoso MO \& Berni RF (2012) Índices agronômicos na cebolinha com doses de sulfato de amônio. Horticultura Brasileira, 30:2375-2382.

Cecílio Filho AB, May A, Pôrto DRQ \& Barbosa JC (2009) Crescimento da cebola em função de doses de nitrogênio, potássio e da população de plantas em semeadura direta. Horticultura Brasileira, 27:49-54.

Corrêa RM, Pinto SIC, Reis ES \& Carvalho VAM (2012) Hydroponic production of fruit tree seedilings. In: ASAO T (Ed.) Hydroponics - A standard methodology for plant biological researches. InTech, Croácia. p.225-244.

Daflon DSG, Freitas MSM, Carvalho AJC, Monnerat PH \& Prins CL (2014) Sintomas visuais de deficiência de macronutrientes e boro em coentro. Horticultura Brasileira, 32:28-34.

Epstein E \& Bloom AJ (2006) Nutrição mineral de plantas: princípios e perspectivas. $2^{\mathrm{a}}$ ed. Londrina, Planta.169p.

Filgueira FAR (2008) Novo manual de olericultura: agrotecnologia moderna na produção e comercialização de hortaliças. $3^{\mathrm{a}}$ ed. Viçosa, UFV. 421p.

Filgueiras RC, Takahashi HW \& Beninni ERY (2002) Produção de alface hidropônico em diferentes condutividades elétricas. Semina: Ciências Agrárias, 23:157-164.

Furlani PR, Silveira LCP, Bolonhezi D \& Faquin V (1999) Cultivo Hidropônico de Plantas. Campinas, Instituto Agronômico. (Boletim Técnico, 180).

Hoagland DR \& Arnon DI (1950) The water-culture method for growing plants without soil. Berkeley, California Agricultural experiment station. 32p. (Circular Técnico, 347.)

Kano C, Cardoso AII \& Villas Bôas RL (2011) Acúmulo de nutrientes pela alface destinada à produção de sementes. Horticultura Brasileira, 29:70-77.

Liu HC, Li JL, Song SW, Sun GW \& Chem RY (2011) Effect of nitrogen and sulphur on the growth and qualities of bunching onion. Advanced Materials Research, 366:127-131.

Liu S, He H, Feng G \& Chen Q (2009) Effect of nitrogen and sulfur interaction on growth and pungency of different pseudostem types of Chinese spring onion (Allium fistulosum L.). Scientia Horticulturae, 12:12-18. 
Luz JMQ, Zorzal Filho A, Rodrigues WL, Rodrigues CR \& Queiroz AA (2009) Adubação de cobertura com nitrogênio, potássio e cálcio na produção comercial de cenoura. Horticultura Brasileira, 27:543-548

Malavolta E (2006) Manual de Nutrição de Mineral de Plantas. São Paulo, Agronômica Ceres. 638p.

Malavolta E, Vitti GC \& Oliveira SA (1997) Avaliação do estado nutricional das plantas: princípios e aplicações. Piracicaba, Potafos. 319p.

Marschner P (2012) Mineral nutrition of higher plants. $3^{\mathrm{a}}$ ed. Australia, Academic Press. 651p.

Nakagawa J \& Rosolem CA (2005) Teores de nutrientes na folha e nos grãos de aveia-preta em função da adubação com fósforo e potássio. Bragantia, 64:441-445.

Novais RF, Alvarez VVH, Barros NF, Fontes RLF, Cantarutti RB \& Neves JCL (2007) (Eds.) Fertilidade do solo. Viçosa, Sociedade Brasileira de Ciência do Solo. 1017p.
Quadros BR, Magro FO, Corrêa CV \& Cardoso AII (2011) Teor de macronutrientes na parte aérea e sementes de plantas de alface em função de doses de composto orgânico com e sem adição de fósforo ao solo. Semina: Ciências Agrárias, 32:1725-1734.

Resende GM, Alvarenga MAR, Yuri JE, Souza RJ, Mota JH, Carvalho JG \& Rodrigues Junior JC (2009) Rendimento e teores de macronutrientes em alface tipo americana em função de doses de nitrogênio e molibdênio em cultivo de verão. Ciência e Agrotecnologia, Lavras, 33:153-163.

Santos JM, Pegoraro RF, Pereira PRG, Fagundes JL, Mistura C, Agostini MAV, Martinez HEP \& Fontes PCR (2005) Comportamento de cebolinha cultivada sob diferentes níveis de cloreto de potássio em solução nutritiva. Ceres, 52:729-738.

Taiz L \& Zeiger E (2004) Fisiologia vegetal. Porto Alegre, Editora Artmed. 719p. 